\title{
Converting Home Spaces into Food Gardens at the Time of Covid-19 Quarantine: all the Benefits of Plants in this Difficult and Unprecedented Period
}

\author{
Adriano Sofo $^{1} \cdot$ Antonino Sofo $^{2}$ \\ Published online: 21 April 2020 \\ (C) Springer Science+Business Media, LLC, part of Springer Nature 2020, corrected publication 2020
}

\begin{abstract}
People are facing uncertain and difficult times in the face of the Covid-19 pandemic. The benefits of plants (psychological, health, economic, productive) in this period of forced isolation can be of key importance. If many of us have to self-isolate in urban or suburban environments, we need something to do to keep our bodies and minds active and fed. In such a challenging scenario, a vegetable garden in home spaces can bring recreational, health, economic and environmental benefits. Regardless of the Covid19 pandemic, there is untapped potential for this kind of garden to impact environmental outcomes, public awareness, and market trends. Home vegetable gardens could provide a small-scale approach to the sustainable use of natural resources, leading towards self-sufficiency, self-regulation, sustainability, and environmental protection.
\end{abstract}

Keywords Covid-19 pandemic $\cdot$ Mediterranean climate $\cdot$ Mental and physical well-being $\cdot$ Home spaces $\cdot$ Plant benefits . Vegetable garden

\section{Introduction}

I am a professor of plant biology and soil chemistry in an Italian university. I and my family are at the moment practicing "social isolation" at home, and this situation will be probably continue for the unforeseeable future. We are allowed to go outside only for the purchase of food and other basic necessities, and the disposal of rubbish, in a radius of 200 meters from home. Because of the extreme contagiousness of Covid19 , unnecessary activity outside is strongly discouraged. Within a few days, our daily life was turned upside down and we were forced to change the old habits. Right now (April 5, 2020), Italy is one of the countries hardest hit by Covid-19 with 88,274 positive diagnoses, 15,915 deaths, and 18,278 recoveries (Dipartimento della Protezione Civile 2020), but we are not sure if the contagion peak has been reached and how long this pandemic will last. As do most

Adriano Sofo

adriano.sofo@unibas.it

1 Department of European and Mediterranean Cultures: Architecture, Environment and Cultural Heritage (DiCEM), University of Basilicata, Via Lanera, 20, 75100 Matera, Italy

276125 Trani, Italy
Italian citizens, I live in a condominium apartment, where 20 families share common spaces and services, without a garden nor plants. In these conditions, one would think we would have a great deal of time on our hands, but on the contrary, this time is unusable. This is because of a general lack of concentration, also because of the daily bad news, and the significant efforts dedicated to the reorganization of family life.

Schools, universities, libraries, museums, and theatres are shut down. Lessons for schoolchildren and students take place only remotely and, as a university lecturer, I am spending at least 8-9 hours per day in front of my laptop for lecturing and tutoring my students, many of whom are concerned about the unprecedented terrible and unimaginable situation. During these laptop-hours, I am also in contact with colleagues and friends all over the world, many of whom I hadn't heard in years, all asking how we are. All these things are substitutes for the life I had but I considered myself very lucky and grateful: I can work from my laptop, an opportunity that not everyone has, and I am physically healthy and mentally active.

Despite these distractions, I had to reduce all this accumulated mental stress, psychological burden and, why not, make myself partly self-sufficient from a food standpoint, while not living in the countryside and having open spaces to cultivate. As a plant and soil biologist, I know that plants are the 
foundation of a multitude of ecosystem services (primary production, provisioning, supporting, regulating and cultural, etc.) and that an environment rich of plants, much more than we are aware of, can guarantee our physical and mental wellbeing (Bratman et al. 2012: Russell et al. 2013; Shwartz et al. 2013; Bratman et al. 2015). My apartment is not so big but I have an empty and unutilized $50-\mathrm{m}^{2}$ terrace upstairs and our Mediterranean climate is mild in the spring, so, I asked myself, why not convert it into a vegetable garden? Besides cultivating and trying to be partially self-sufficient for fruit and vegetables (that are expensive and hard to find now), this could give me psychological benefits. There is an association between home gardening and physical and mental well-being, and this has been demonstrated for various categories of people at risk (Grabbe et al. 2013; van Lier et al. 2017; John et al. 2016; Quick et al. 2017). I had a lot of material in my garage, some pipes, shelves, supports, other stuff, and hardware. What I didn't have, I would order online. Then, I acted scientifically, calculating the total costs, needed materials and items, plant species to be cultivated, types of soil and pots, production per unit of surface, psychological effects of plants on my family. Documenting everything, taking photographs, and updating a personal/laboratory diary were my imperatives. We all, humans, plants, and soil would be part of an experiment, and all this without moving from home.

Here I present a short paper on my experience, focusing on the benefits of plants (psychological, health, economic, productive) in this period of forced isolation. If many of us have to self-isolate in urban or suburban environments characterized by the lack of spaces and resources, which negatively affects our brain activity (Lambert et al. 2015), we need something to do to keep our bodies and minds active and fed. I couldn't think of better work than setting up a home vegetable garden. I know that the idea seems, at a first glance, strange and inappropriate - considering the number of current and future problems - but, as a scientist, I felt I had to do it. With people now facing uncertain and difficult times in the face of Covid-19, I thought I might dedicate this article to the positive action of plants and see how they can help us.

\section{Some Brief Preliminary Information}

I have always been interested in urban permaculture, aimed at producing food in urban areas and promoting energy efficiency and self-production. Because it starts from personal initiative and your own home, it is here, more than in all the other sectors of permaculture, that the imagination and the flair of the solutions adopted are surprising. Urban permaculture can be concrete and pragmatic, aimed at the production of food in urban areas, replacing ornamental plants with edible species.

The selection of plant species to cultivate in outside home spaces should be based primarily on their ability to cope with the harsh conditions of the urban environment, such as high wind and irradiance, lack of organic material and nutrients, and intermittent drought (Pavao-Zuckerman 2008). Therefore, careful plant selection should be integrated into outside space design (Lee et al. 2014; John et al. 2016; Chaudhary et al. 2019). Urban habitats are unique and harsh environments for established plant communities, largely because of increased abiotic stresses, such as disturbance, pollution, drought, radiation, heat and microclimate extremes, but also because of the reduction of colonization and modifications in soil microbial diversity (e.g., mycorrhizas or bacteria). Another additional difficulty, confirmed by my usual plant dealer, is that there is a rush on vegetable seedlings in garden centers because many more people are now wanting to grow their food. The spread of Covid-19 has caused panic buying at supermarkets, so many families are skipping the supermarket and heading to their local garden center to grow their own and become self-sufflcient. Therefore, it is often necessary to wait on average one week to get seedlings (starting from the seed is not advisable, as it would take too long).

In my small way, I will show you what you could do in your apartment space, on a balcony, a terrace or in a little courtyard. Mine is a very practical example of urban permaculture and I hope that could contribute to lightening your stress in this complicated period.

\section{Let's Get to Work}

From various sites on the web, it is possible to draw countless ideas for designing and managing a small home garden. Regardless of space and financial availability, you devise your slice of food independence. The most important thing is to start and be ready to try, without being afraid of making mistakes. A vegetable garden in the city has many advantages. First, you will produce healthy vegetables for yourself. Then, there is the psycho-physical well-being that comprises doing a little physical activity and enjoying the satisfaction of seeing your vegetables grow (Reed et al. 2013). Even at the community level, a vegetable garden has its positive sides: a green spot in the cement brightens the view, purifies the air, and cools the environment because of plant transpiration. On an ecological level, an urban garden is a refuge and a shelter for many animals - you cannot imagine how many.

But let's proceed step by step. Here is my decalogue based on my experience at the moment. For clarity, please note that I describe a garden in a Mediterranean environment in the springtime.

1) Water is the most important issue. On terraces, there are usually rain gutters. Instead of wasting rainwater, which moreover is of excellent quality, as it is salt-free, just adapt a tank (in Fig. 1, a 300-1 resin tank) to the 
Fig. 1 Irrigation and composting systems
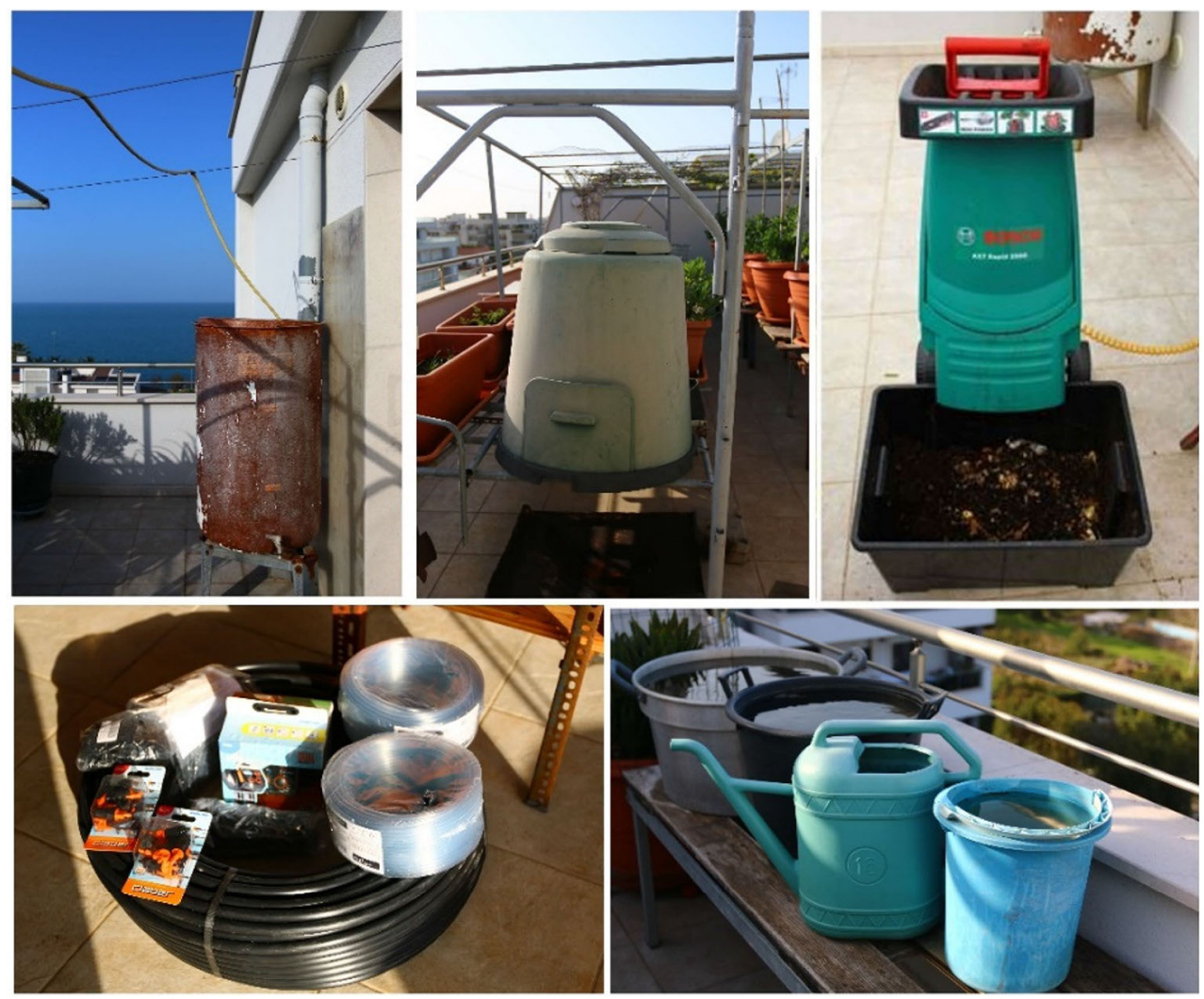

collection of rainwater. The lid, necessary to avoid water evaporation, has been perforated to facilitate the entry of the tube. Considering the heat of a terrace in the summer months and the outrageous demand for water for transpiration and evapotranspiration, an additional reserve of water is useful and falls within the perspective of sustainability and saving of natural resources. In a few hours of moderate rain, the tank will fill. If in excess, the accumulated water could be also very useful for cleaning the terrace, which gets dirty when it is transformed into a vegetable garden. In the long run, it might be better to buy a pressure washer to save more water. After the first initial investment (not excessive), you will save a lot of water. Other simpler tanks and buckets can also collect water. For aqueduct water, I recommend an irrigation system with an electronic control unit that sends water to the root system of the plants, reduces losses by evaporation, water consumption and costs of the water bill. Here, the higher costs for the irrigation system should be taken into account.

2) The scaffolding. Here too there are various solutions. If we use large pots (a choice that I recommend), they should be raised and not positioned on the ground. This is useful both to better clean the terrace and to not tire you out. The most sustainable choice is the perforated steel or aluminum beams used to construct the shade canopies in the parking areas of shopping malls and supermarkets in Europe, and they are inexpensive (Fig. 2). By positioning several poles, the structure will be light, stable and will not bend even with the wind because the perforated surface does not offer much resistance. This kind of structure is very useful if you want to train a wild vine (Ampelopsis brevipedunculata and Parthenocissus quinquefolia) or wisteria (Wisteria spp.), or other climbing plants that also have a decorative and shading function. In Mediterranean climates, the hot late spring/summer days can raise soil temperature in the pots to even reach $40-50{ }^{\circ} \mathrm{C}$ and air temperature 30 $35^{\circ} \mathrm{C}$, so it is advisable to use shade cloth or shading vegetation on the scaffolding to avoid burning roots and shoots of the plants so laboriously cultivated.

3) The containers. Here you are spoiled for choice but remember that we want to recycle water and save money. We will therefore not buy expensive pots. As simple containers, you can also use inexpensive black/ transparent plastic containers that you will drill at the base for drainage, or the wooden boxes from greengrocers (nowadays very rare to find). If the choice falls on the pots, one must be careful and containers without good drainage and/or not transpiring are not recommended. Here, it is easy for the roots to suffer from high heat or water stagnation. The best choice would be that of the classic rectangular brown clay pots, but they are heavy, fragile, and expensive (Fig. 3). On the other side, 

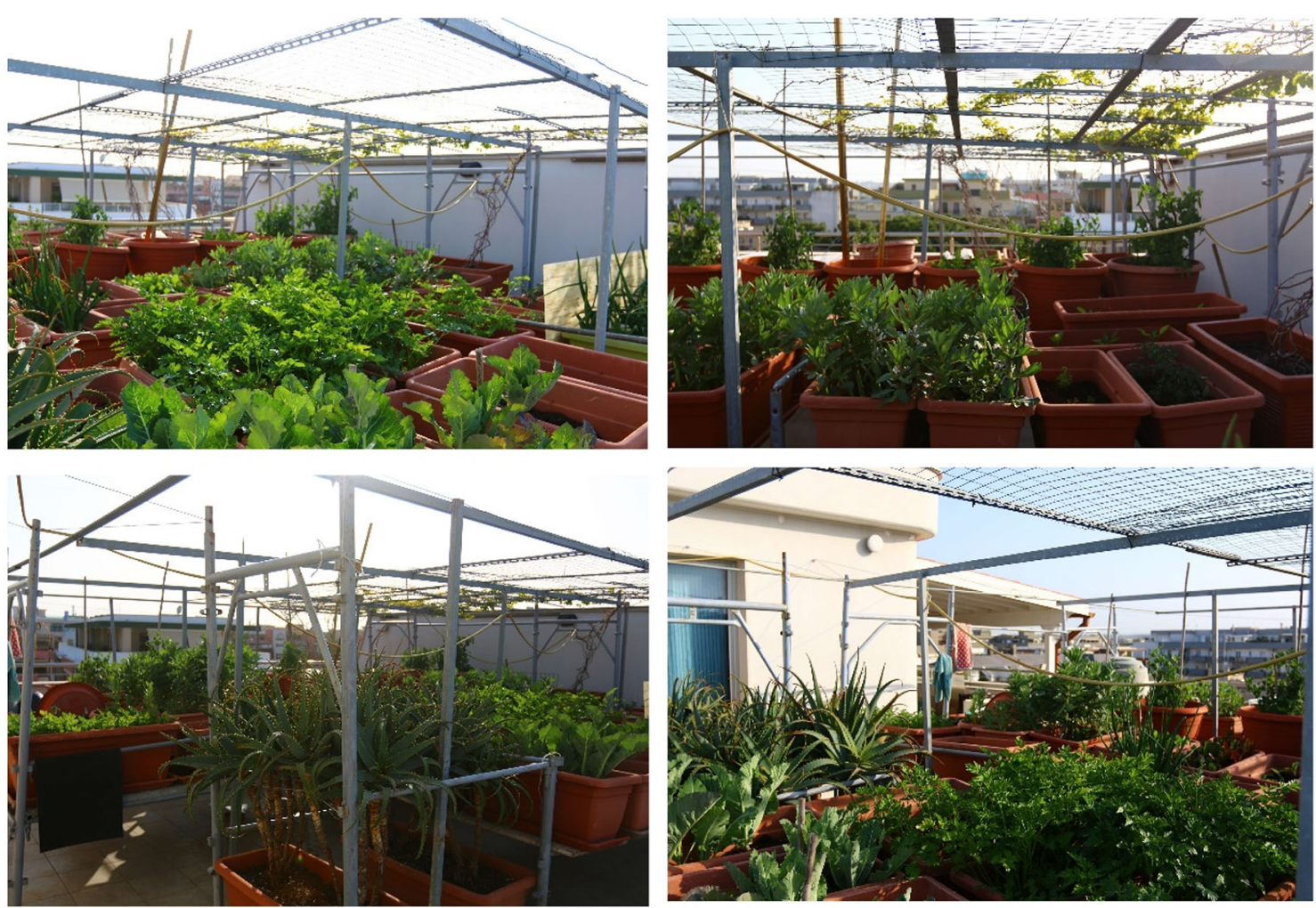

Fig. 2 The recycled scaffolding

the plastic ones are light, not expensive, and long-lasting. Instead, we will use common plastic containers or other containers to transport soil, grass clippings, root residues, and compost. If desired, the containers can be built with wooden beams and sheets of various kinds but, considering that it is a terrace and that we must avoid water infiltration and stagnation, better to go with the clay or plastic pots (or a mixture of both).

4) What to plant? Here too the choice is wide. Since the surface, even if you use several pots, is limited, all

Fig. 3 The containers used
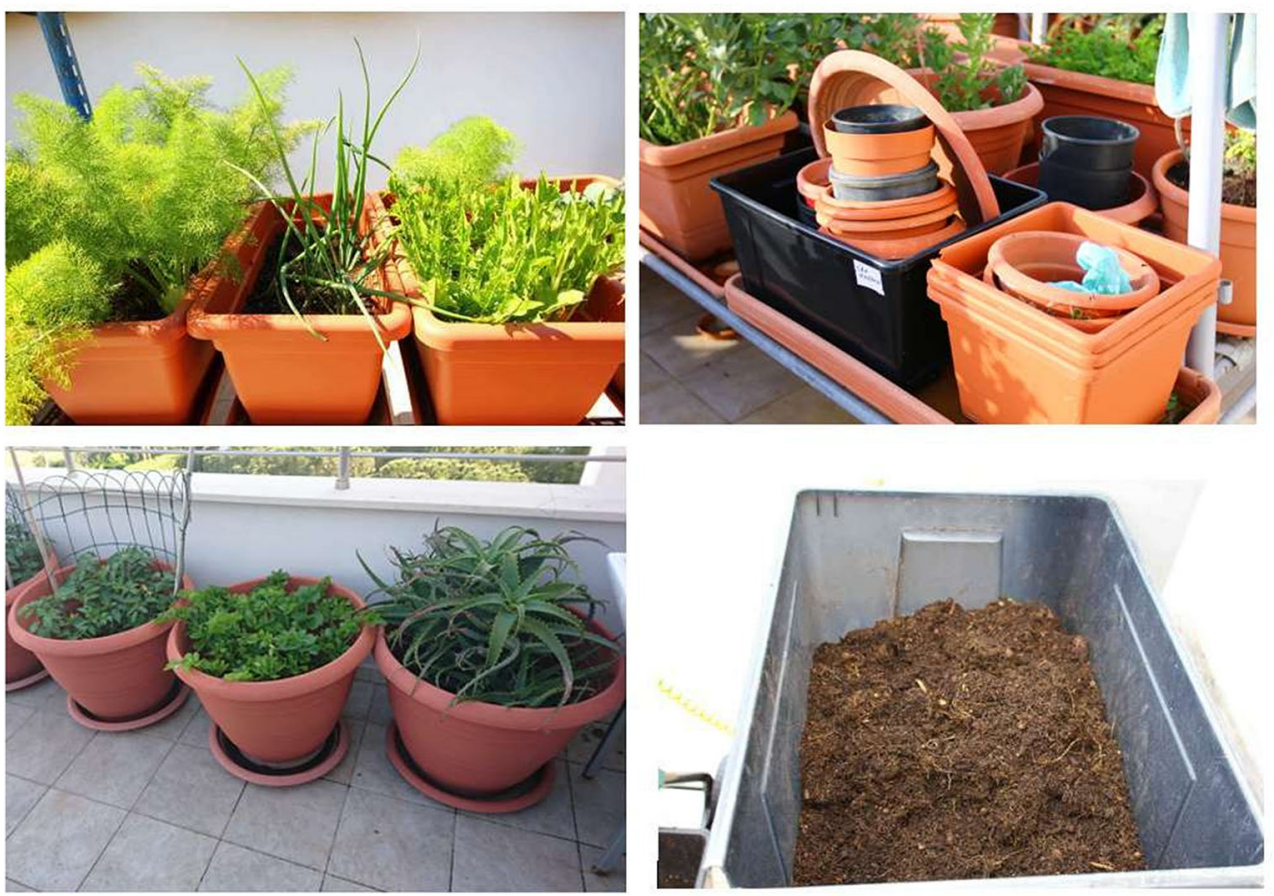
species that have a too low total fruit/biomass ratio (e.g., legumes) are not recommended. You would risk wasting too much space and having a minimum harvest. In springtime, you can grow different cultivars of lettuce (Lactuca sativa), zucchini (Cucurbita pepo), onion (Allium cepa), chicory (Cichorium intybus), rocket (arugula) (Eruca sativa), green and red beet (Beta vulgaris), fennel (Foeniculum vulgare), chive (Allium schoenoprasum), carrot (Dacus carota), strawberry (Fragaria spp.), late cauliflower/broccoli (Brassica oleracea) and spinach (Spinacia oleracea), early potato (Solanum tuberosum), tomato (Lycopersicon esculentum), eggplant (Solanum melongena) and sweet/spicy pepper (Capsicum spp.), and some fresh legumes, such as broad bean (Vicia faba), fresh bean (Phaseolus vulgaris), and pea (Pisum sativum) (Fig. 4). Tomatoes and fresh legumes need support when they grow, such as wire or bamboo and plastic posts. Each season has its particular harvest, so you will follow the rhythms marked by nature, and together you will have vegetables at zero meters. The potting soil should be organic and perhaps mixed with manure (maximum $15 \% \mathrm{w} / \mathrm{w}$ ), with an expanded clay base to avoid water stagnation. It is best to start from seedlings rather than seed. The cost of the seedlings is not high, so starting from seed, especially for some broad-leaved vegetables, it is also sometimes uneconomical and requires too much time and too much care. After the initial investment of soil, remember that the subsequent additions could be produced from compost. If needed, you can carry out a mineral nitrogen fertilization, particularly recommended in spring.

5) Other crops. If you have a free corner left, you can also grow some officinal plants and spices, such as basilicum (Ocimum basilicum), parsley (Petroselinum crispum), celery (Apium graveolens), rosemary (Salvia rosmarinus), sage (Salvia officinalis), thyme (Timus vulgaris), marjoram (Origanum majorana), oregano (Origanum vulgare), melissa (Melissa officinalis), mint (Mentha spp.) and lavender (Lavandula officinalis - whose dry inflorescences are excellent for perfuming linen), or saplings (these latter better in circular pots placed on the ground), such as olive (Olea europaea), pomegranate (Punica granatum) and mulberry (Morus spp.), or other useful and undemanding plants, such as aloe (Aloe spp. - whose inner leaf is a strong antioxidant and can be used for healing wounds and burns), citronella (Cymbopogon nardus - mosquito repellent) and prickly pear (Opuntia ficus-indica) (Fig. 5). You might put in some ornamental plants but remember that you are in a permaculture regime and therefore you must not have too many demands.

6) The compost. Another important consideration is the recycling of waste materials. The vegetable biomass of waste, even of a small vegetable garden, can be high and mixed with waste that would end up in the garbage (fruit skins, vegetable residues, eggshells, coffee grounds, tea bags, etc.) it becomes an excellent starting point for the production of compost. You can also add the shredded roots of the plants you want to replace and recover this precious soil. The waste of a vegetable garden has an optimal carbon/nitrogen ratio (around 20-30), so it is quickly transformed into soil. The soil residues that remain tied to the roots of old plants can be chopped and mixed with the rest, thus providing a natural starter of bacteria and saprophytic fungi. You will notice that your residues will smell first of fruit and vegetables, then of garbage, then of manure, and finally of fresh soil. At that point, compost became humus. The latter has many advantages: it is a fertilizer rich in carbon, nitrogen, and phosphorus, makes the soil soft and improves its structure (it is, therefore, a soil conditioner), keeps more water when it does not rain, contains billions of
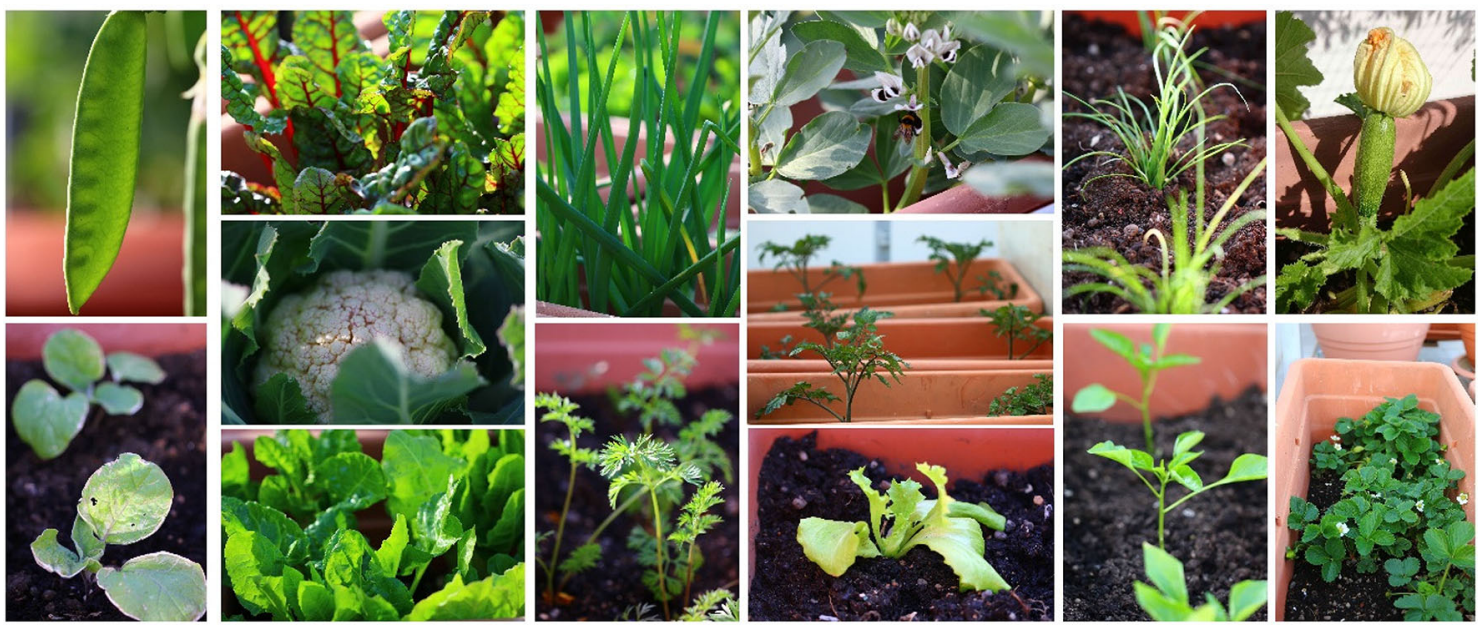

Fig. 4 Edible plants 

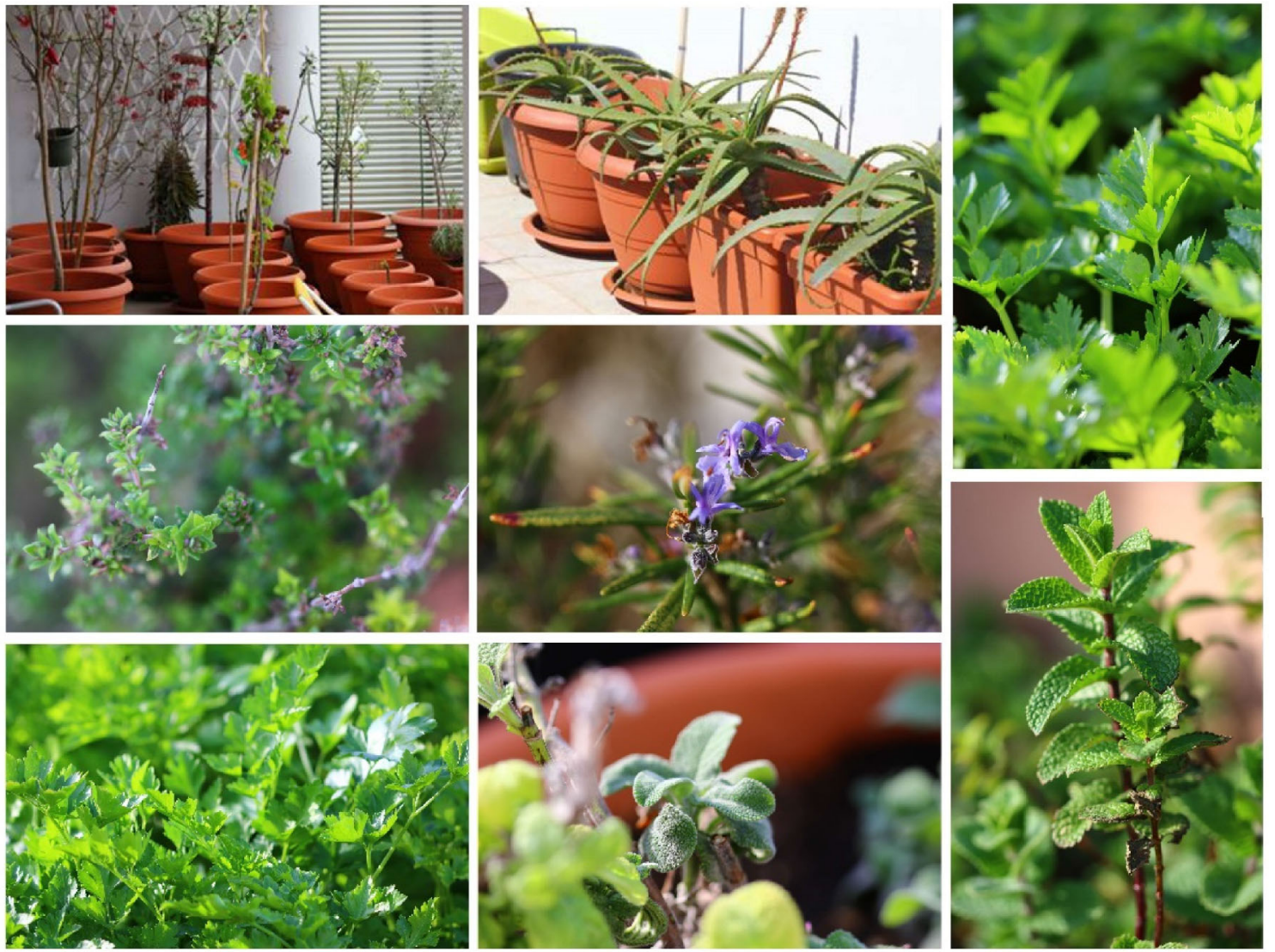

Fig. 5 Saplings and officinal plants

microorganisms (many of which with antibiotic effects against phytopathogens, others with plant growthpromoting action) and many others. For chopping, you can use an electric shredder that chops everything except very hard material, such as kernels (Fig. 1). With the same volume, smaller pieces offer a larger surface area to the microbial attack and therefore composting is faster and more effective. To contain the compost, you can buy
Fig. 6 Some animal hosts of the home vegetable garden
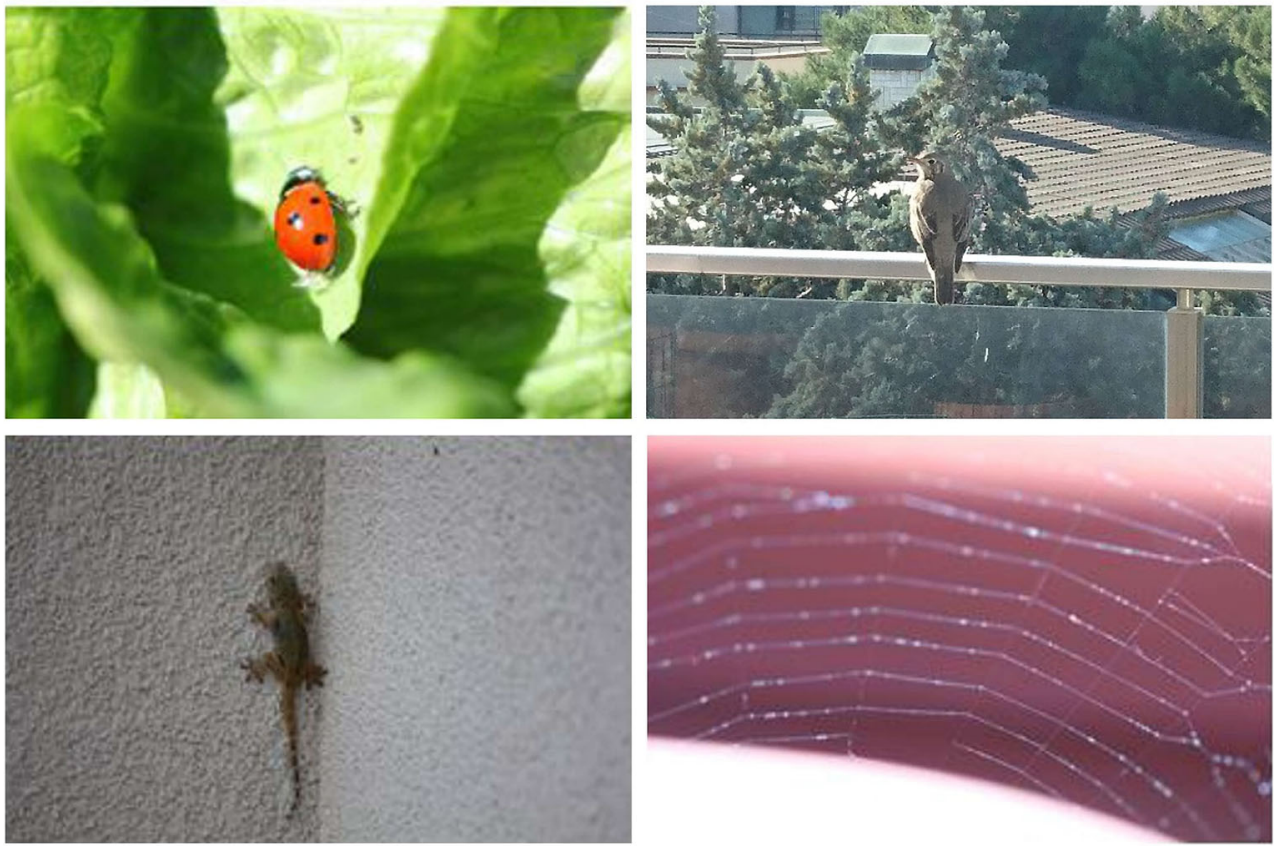

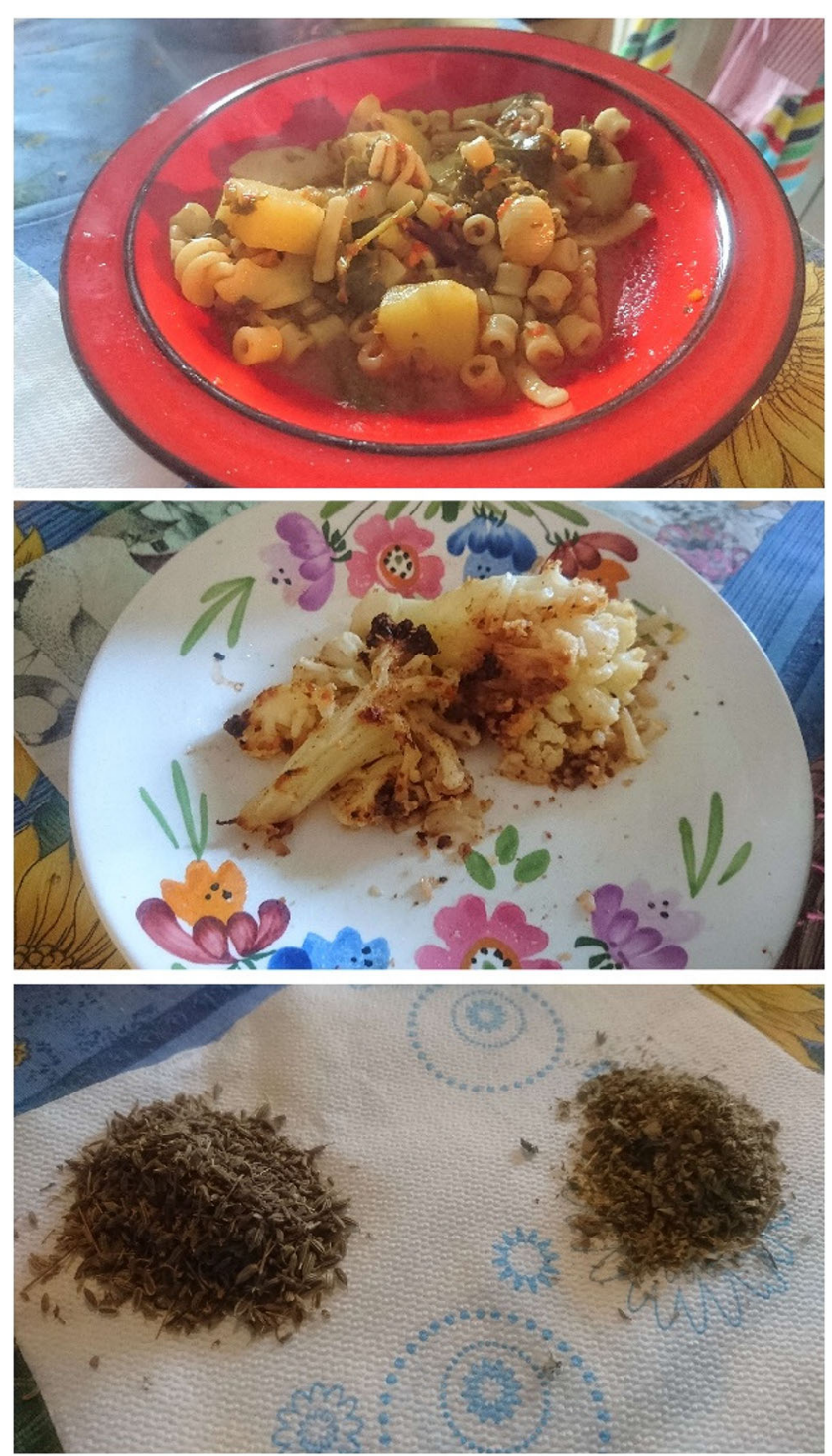

Fig. 7 Two dishes prepared with the products from the home vegetable garden, and sun-dried fennel seeds and oregano leaves (kindly prepared by Annamaria Galluzzi)

a compost bin (there are various sizes but, for a family of four, a 300-1 one is more than enough) or, with a little patience, you can build it (Fig. 1). It will surprise you how soon it will fill up and how much less waste you will produce. On warm days, when the bacterial metabolism is high, turning it now and then with a hoe, the compost will be ready in about three months. In this way of recycling you can produce fresh soil in situ and save on the soil buy.

7) Biodiversity. Your home garden is also a cure-all for passing species. In my case, it is not unusual to see plenty of ladybugs (beneficial because they are carnivorous), various spiders, geckos, lizards, bats (attracted by insects), passerines, turtle doves, magpies, and thrushes (Fig. 6). Unfortunately, since your vegetable garden is free of pesticides (less pollution), it is normal for pests such as mealy cochineals that attack lemon and olive trees, nematodes that affect tomato roots, and finally cabbagewhite butterflies that lay eggs from which voracious leaf-eating caterpillars will appear, to come, but with patience, by hand or with natural remedies, these can be kept at bay.

8) Personal satisfaction. The home vegetable garden is satisfying because looking at the vegetables and fruit you have cared for gives a pleasant sense of fulfilment. A pod of a pea plant that tries to climb anywhere or the contrast of colors of a red beet leaf can enchant you. You can make yourself a salad, a fresh sauce or turnip greens, au gratin cauliflower, a vegetable soup with pasta, cooking the vegetables you have harvested, or use the sun-dried leaves or seeds of officinal plants as spices or ingredients for your dishes (Fig. 7). With a vegetable garden at home, the value of the products is their real worth, because it only takes into account personal work and there are no additional costs, such as fuel for transportation, synthetic fertilizers, plant protection products, marketing, advertising.

9) The costs. The terrace garden allows you to save money in the medium-term, even if this is not the only purpose. Of course, there is an initial investment (Table 1). We can find much of the listed material for free, build
Table 1 Approximate costs for a 50-m2 home vegetable garden

\begin{tabular}{|c|c|c|}
\hline & Item & Cost \\
\hline \multirow[t]{11}{*}{ Initial costs } & Water tank (300 L) & About $100 €$ or recycled \\
\hline & Automated drip irrigation system & About $200 €$ (optional) \\
\hline & Scaffolding & Max $300 €$ or recycled \\
\hline & Universal potting soil & $\operatorname{Max} 350 €$ \\
\hline & $30-40$ plastic pots $(100 \times 44 \times 40 \mathrm{~cm})$ & About $450 €$ \\
\hline & Shading net & About $50 €$ (optional) \\
\hline & Shredder & About $150 €$ (optional) \\
\hline & Compost bin $(300 \mathrm{~L})$ & About $50 €$ or built \\
\hline & Total initial investment & $800-1650 €$ \\
\hline & Aqueduct water consumption & About $150 €$ year- 1 \\
\hline & Seedlings & About $100 €$ year- 1 \\
\hline \multirow[t]{2}{*}{ Annual costs } & Additional soil & Max $100 €$ year- 1 (optional) \\
\hline & Total annual investment & $250-350 €$ year -1 \\
\hline
\end{tabular}


something, and find excellent offers on the internet. Therefore, the cost of installation of a home vegetable garden is variable, and it could be much lower than the one I calculated in Table 1. Besides, you don't have to do all the things I have listed. It would be better to start on a small scale and expand step by step. As the garden will produce kilos of fresh vegetables (we make an average of $100-150 \mathrm{~kg} \mathrm{year}^{-1}$ ), at an average price of $2-5 € \mathrm{~kg}^{-1}$, you can recover annual management costs in a brief time. The initial costs are not excessive, if you consider the satisfaction of eating home-grown vegetables.

10) Not all apartments have large terraces or courtyards to devote to the cultivation of vegetables; often the area is limited to a balcony or even a windowsill. Even in cases like these, it is possible to successfully grow a small vegetable garden. The key to success lies in the choice of species to be cultivated, giving preference to those with limited development such as aromatic plants (basil, parsley, rosemary, thyme, sage), plants that combine an aesthetic effect with the production of fruits (cherry tomatoes, chili pepper, etc.), and plants of rapid and safe results (lettuce, chicory, rocket, etc.). So, enjoy your home vegetable garden!

\section{Conclusions}

A vegetable garden in home spaces can provide recreation, enhance physical and mental health, and provide economic and environmental benefits (Dunnett and Qasim 2000; Hartig et al. 2014; Jennings and Johnson Gaither 2015). There are no greenhouse gas emissions, no use of synthetic fertilizers and pesticides, no leaching losses. Regardless of practical challenges and the existential difficulties we face, there is untapped potential for home vegetable gardens to influence environmental outcomes, citizens' consciousness, and market trends. It is time to think about a new way of living that starts from daily activities, with a small-scale and bottomup approach, based on sustainable use of natural resources and promotion of a subsistence economy and bartering, aimed at lasting well-being in generations both in material terms (food and energy) and psychological terms, able to integrate various disciplines (such as agriculture and animal husbandry, forestry, biology, architecture, engineering, but also economics, sociology, philosophy, and psychology), tending towards selfsufficiency, self-regulation, sustainability, and environmental protection. Bill Mollison, who coined the term "permaculture" in the 1970s, said that "a culture cannot survive long without a sustainable agricultural base and ethics of land use."

My heartfelt suggestion is to stay safe at home now and consider that this pandemic could be an opportunity for a whole new - and likely better - world. Covid-19 is the last warning that gives us time to reconsider human behavior from global warming to the ever-increasing intensity and speed of activities, all of which are related to the principle of the capitalistic system. This pause can help us deliberate how all this can be transformed into a sustainable system; maybe it is a big chance!

\section{References}

Bratman, G.N., Daily, G.C., Levy, B.J., Gross J.J. (2015). The benefits of nature experience: Improved affect and cognition. Landscape and Urban Planning, 138, 41-50.

Bratman, G.N., Hamilton, J.P., Daily G.J. (2012). The impacts of nature experience on human cognitive function and mental health. Annals of the New York Academy of Sciences, 1249, 118-136.

Chaudhary, V.B., Sandall, E.L., Lazarski, M.V. (2019). Urban mycorrhizas: predicting arbuscular mycorrhizal abundance in green roofs. Fungal Ecology 40, 12-19.

Dipartimento della Protezione Civile (2020). Covid-19 Italia - Monitoraggio della situazione. http://opendatadpc.maps.arcgis.com/apps/ opsdashboard/index.html\#/b0c68bce2cce478eaac82fe38d4138b1 (accessed 31 March 2020).

Dunnett, N., Qasim, M. (2000). Perceived benefits to human well-being of urban gardens. HortTechnology 10 (1), 40-45. https://doi.org/10. 21273/HORTTECH.10.1.40

Grabbe, L., Ball, J., Goldstein, A. (2013). Gardening for the mental wellbeing of homeless women. Journal of Holistic Nursing, 31 (4), 258 266. https://doi.org/10.1177/0898010113488244

Hartig, T., Mitchell, R., de Vries, S., Frumkin, H. (2014). Nature and health. Annual Review of Public Health, 35, 207-228.

Jennings, V., Johnson Gaither, C. (2015). Approaching environmental health disparities and green spaces: An ecosystem services perspective. International Journal of Environmental Research and Public Health, 12, 1952-1968.

John, J., Kernaghan, G., Lundholm, J. (2016). The potential for mycorrhizae to improve green roof function. Urban Ecosystems, 20 (1), $113-127$.

Lambert, K.G., Nelson, R.J., Jovanovic, T., Cerdá, M. (2015). Brains in the city: Neurobiological effects of urbanization. Neuroscience and Biobehavioral Reviews, 58, 107-122.

Lee, K.E., Williams, K.J.H., Sargent, L.D., Farrell, C., Williams, N.S. (2014) Living roof preference is influenced by plant characteristics and diversity. Landscape and Urban Planning, 122, 152-159.

Pavao-Zuckerman, M.A. (2008) The nature of urban soils and their role in ecological restoration in cities. Restoration Ecology, 16 (4), 642-649.

Quick, J.S., Robishaw, S.B., Baylor, K.A., Snyder, D.I., Han, J.J. (2017). Vegetable garden as therapeutic horticulture for patients with chronic pain. Pain Medicine, 18 (11), 2252-2254. https://doi.org/10.1093/pm/ pnx065 
Reed, R., Wood, C., Barton, J., Pretty, J.N., Cohen, D., Sandercock, G.R.H. (2013). A repeated measures experiment of green exercise to improve self-esteem in UK school children. PLoS ONE, 8 (7), e69176.

Russell, R., Guerry, A.D., Balvanera, P., Gould, R.K., Basurto, X., Chan, K.M.A., Klain, S., Levine, J., Tam, J. (2013). Humans and nature: How knowing and experiencing nature affect well-being. Annual Review of Environment and Resources, 38, 473-502.
Shwartz, A., Turbé, A., Simon, L., Julliard, R. (2013) Enhancing urban biodiversity and its influence on city-dwellers: An experiment. Biological Conservation, 171, 82-90.

van Lier, L.E., Utter, J., Denny, S., Lucassen, M., Dyson, B., Clark, T. (2017). Home gardening and the health and well-being of adolescents. Health Promotion Practice, 18 (1), 34-43.

Publisher's Note Springer Nature remains neutral with regard to jurisdictional claims in published maps and institutional affiliations. 